\title{
A bibliometric study of scientific research conducted on second-generation antipsychotic drugs in Singapore
}

Francisco López-Muñoz
Raquel $\underline{\text { Moreno }}^{1}$, MN, Juan de Dios $\underline{\text { Molina }}^{1,5}, \mathrm{MD}, \mathrm{PhD}$, Gabriel $\underline{\text { Rubio }}{ }^{6}, \mathrm{MD}, \mathrm{PhD}$, Concha $\underline{\text { Noriega }}^{1}, \mathrm{MN}, \mathrm{PhD}$, Miguel Ángel Pérez-Nieto ${ }^{1}$, PsyD, PhD, Cecilio Álamo ${ }^{2}$, MD, PhD

INTRODUCTION A bibliometric study was carried out to ascertain the volume and impact of scientific literature published on second-generation antipsychotic drugs (SGAs) in Singapore from 1997 to 2011.

METHODS A search of the EMBASE and MEDLINE databases was performed to identify articles originating from Singapore that included the descriptors 'atypic* antipsychotic*', 'second-generation antipsychotic*', 'clozapine', 'risperidone', 'olanzapine', 'ziprasidone', 'quetiapine', 'sertindole', 'aripiprazole', 'paliperidone', 'amisulpride', 'zotepine', 'asenapine', 'iloperidone', 'lurasidone', 'perospirone' and 'blonanserin' in the article titles. Certain bibliometric indicators of production and dispersion (e.g. Price's Law on the increase of scientific literature, and Bradford's Law) were applied, and the participation index of various countries was calculated. The bibliometric data was also correlated with some social and health data from Singapore, such as the total per capita expenditure on health and gross domestic expenditure on research and development.

RESULTS From 1997 to 2011, a total of 51 articles on SGAs in Singapore were published. Our results suggested non-fulfilment of Price's Law ( $r=0.0648$ after exponential adjustment vs. $r=0.2140$ after linear adjustment). The most widely studied drugs were clozapine (21 articles), risperidone (16 articles) and olanzapine ( 8 articles). Division into Bradford zones yielded a nucleus occupied by the Journal of Clinical Psychopharmacology (6 articles) and the Singapore Medical Journal (4 articles). The analysed material was published in a total of 30 journals, with the majority from six journals. Four of these six journals have an impact factor greater than 2.

CONCLUSION Publications on SGAs in Singapore are still too few to confirm an exponential growth of scientific literature.

Keywords: atypical antipsychotics, bibliometry, schizophrenia, second-generation antipsychotics, Singapore

\section{INTRODUCTION}

Schizophrenia is a severe mental illness that constitutes a prototype of psychiatric disorders, although its aetiopathogenic basis is not entirely known. According to epidemiological studies, its prevalence fluctuates between $0.5 \%$ and $1.0 \%$ in the population. ${ }^{(1)}$ The World Health Organization classifies this illness as among the top ten disorders causing a greater disability in the adult population. ${ }^{(2)}$

During the last 60 years and following the introduction of chlorpromazine into clinical practice, the mainstay treatment of schizophrenia has been based on the use of antipsychotic drugs. ${ }^{(3)}$ The first drugs, termed 'first-generation drugs' (i.e. classical or typical drugs), showed great efficacy in reducing positive symptoms (e.g. hallucinations and delusions); however, a main limitation of these drugs was the onset of extrapyramidal side effects (EPS). The reintroduction of clozapine in the United States - a neuroleptic commercialised in the 1960s that was later withdrawn due to its ability to induce agranulocytosis ${ }^{(4)}-$ brought a dramatic change in research expectations. This agent, apart from causing few EPS, showed clinical efficacy in improving both positive and negative symptoms in patients who were refractory to other first-generation antipsychotic drugs. ${ }^{(5)}$ The reintroduction of clozapine, together with the introduction of risperidone in 1993, ${ }^{(4)}$ opened the door to 'atypical antipsychotics, ${ }^{\prime(6)}$ also known as second-generation antipsychotic drugs (SGAs).

The advances achieved in the field of antipsychotic drugs in the past 30 years have been incredibly important, leading to the clinical introduction of numerous SGAs (Table I). These agents have notably improved the quality of life of psychotic patients and contributed toward reducing the stigma associated with such a crippling disease. (7) Following the clinical introduction of new antipsychotics in 1993 and the subsequent authorisation of their use for the treatment of bipolar disorder in 2003, research efforts related to these drugs saw a manifold increase. ${ }^{(8)}$ We hypothesised that this increase in research would have correlated with an increase in the volume of published scientific literature on these drugs and thus proceeded to analyse published scientific literature on SGAs in Singapore.

${ }^{1}$ Faculty of Health Sciences, Camilo José Cela University, ${ }^{2}$ Department of Pharmacology, University of Alcalá, Madrid, Spain, ${ }^{3}$ Department of General Psychiatry, Institute of Mental Health, Singapore, ${ }^{4}$ Departments of Psychiatry, Wan Fang Medical Center and School of Medicine, Taipei Medical University, Taipei, Taiwan, ${ }^{5}$ Acute Inpatients Unit, DrR Lafora Psychiatric Hospital, ${ }^{6}$ Department of Psychiatry, 'Doce de Octubre' University Hospital, Complutense University, Madrid, Spain

Correspondence: Prof Francisco López-Muñoz, Faculty of Health Sciences, Camilo José Cela University, C/ Castillo de Alarcón, 49, Urb Villafranca del Castillo, Villanueva de la Cañada, 28692 Madrid, Spain. francisco.lopez.munoz@gmail.com 
Table I. Clinical development of second-generation antipsychotic drugs.

\begin{tabular}{|c|c|c|c|}
\hline Drug & Company name & Year & Country of launch \\
\hline Clozapine & Wander Laboratories & $1972^{*}$ & Switzerland \\
\hline Zotepine & Fujisawa & $1982^{+}$ & Japan \\
\hline Amisulpride & Synthelabo & 1986 & Portugal \\
\hline Risperidone & Johnson \& Johnson & 1993 & UK/Canada \\
\hline Sertindole & Abbott Laboratories & $1996 \neq$ & UK \\
\hline Olanzapine & Eli Lilly & 1996 & USA/UK \\
\hline Quetiapine & AstraZeneca & 1997 & USA/UK \\
\hline Ziprasidone & Pfizer & 2001 & USA \\
\hline Perospirone & Dainippon Sumitomo Pharma & 2001 & Japan \\
\hline Aripiprazole & Otsuka/Bristol-Myers Squibb & 2002 & USA \\
\hline Paliperidone & Janssen Pharmaceutica & 2007 & USA \\
\hline Asenapine & Schering-Plough & 2009 & USA \\
\hline Iloperidone & Novartis AG & 2009 & USA \\
\hline Lurasidone & Dainippon Sumitomo Pharma & 2011 & USA \\
\hline
\end{tabular}

${ }^{*}$ Reintroduced in 1990 in USA and UK after being withdrawn from the market in $1975 .{ }^{\dagger}$ Commercialised by Astellas in Germany in $1990 .{ }^{\ddagger}$ Marketing authorisation was suspended by the European Medicines Agency (EMA) in 1998 and the drug was withdrawn from the market. In 2002, based on new data, the EMA suggested that sertindole could be reintroduced for restricted use and with extensive electrocardiography monitoring. UK: United Kingdom; USA: United States of America [Sources: PharmaProjects, PJB Publications Ltd, 2012; R\&D Insight, ADIS International, 2012; International Marketing Services Health, 2012]

Although Singapore is an emergent country with a highly developed, market-based economy, it has a short psychiatric history. A substantial proportion of people in Singapore rely on a mixture of Western and traditional medicines, and seek help from spiritual healers or practitioners of traditional medicine; in some instances, this results in delayed psychiatric treatment. ${ }^{(9)}$ There are about 115 practising psychiatrists in Singapore, giving a psychiatrist-to-population ratio of 2.6/100,000, which is low compared to other developed countries such as the United States of America (USA), which has a psychiatrist-to-population ratio of $13.7 / 100,000 .{ }^{(10)}$ However, the Ministry of Health in Singapore has supported the local development of the field of psychiatry and the use of evidence-based practice guidelines; it has also published clinical practice guidelines on schizophrenia ${ }^{(10)}$ and bipolar disorder ${ }^{(11)}$ to provide doctors and patients in Singapore with evidence-based guidance on the management of these disorders.

Bibliometric studies are useful tools for assessing the social and scientific relevance of a given discipline or field, and may be of particular interest to different health professionals such as policy makers, researchers and clinicians. ${ }^{(12)}$ In recent years, our group has, using a bibliometric approach, studied the evolution of scientific literature in psychiatry pertaining to the different aspects of different psychiatric disorders and the specific therapeutic modalities being pursued within the field of psychopharmacology. ${ }^{(8,13-17)}$ In the present study, we had the specific aim of conducting a bibliometric assessment of the scientific literature published on SGAs in Singapore from 1997 to 2011 .

\section{METHODS}

Both the MEDLINE (Index Medicus, US National Library of
Medicine, Bethesda, Maryland, USA) and Excerpta Medica (Elsevier Science Publishers, Amsterdam, Netherlands) databases were used in this bibliometric study. These two databases are considered to be the most exhaustive databases in the biomedical field, with participation in the EMBASE Biomedical Answer web (Elsevier BV, Amsterdam, Netherlands).

Using remote downloading techniques, articles published from 1997 to 2011 containing the descriptor 'Singapore' in the AD (i.e. address of authors) field and the descriptors 'atypic* antipsychotic*', 'second-generation antipsychotic*', 'clozapine', 'risperidone', 'olanzapine', 'ziprasidone', 'quetiapine', 'sertindole', 'aripiprazole', 'paliperidone', 'amisulpride', 'zotepine', 'asenapine', 'iloperidone', 'lurasidone', 'perospirone' and 'blonanserin' in the $\mathrm{TI}$ (i.e. title) field were retrieved. All articles on antipsychotic drugs (typical and atypical) published in Singapore during this period were also included. For the purpose of this study, all publications (original articles, brief articles, reviews, editorials or letters to the editor) were considered. Duplicated articles were omitted. The papers were categorised into four groups ('experimental pharmacology', 'clinical efficacy', 'tolerance and/or safety' and 'not specified') using manual coding after a brief study of the titles and/or abstracts of the articles.

This study, which was based entirely on an analysis of secondary published materials, was approved by the Research Ethics Committee (Comité de Ética de la Investigación) of Camilo José Cela University, Madrid, Spain, and conformed to the provisions of the Declaration of Helsinki (Edinburgh revision, 2000).

Price's Law was among the bibliometric indicators of production applied. ${ }^{(18)}$ Price's Law reflects exponential growth, which is a fundamental aspect of scientific productivity. To assess whether the growth of scientific publications on SGAs 


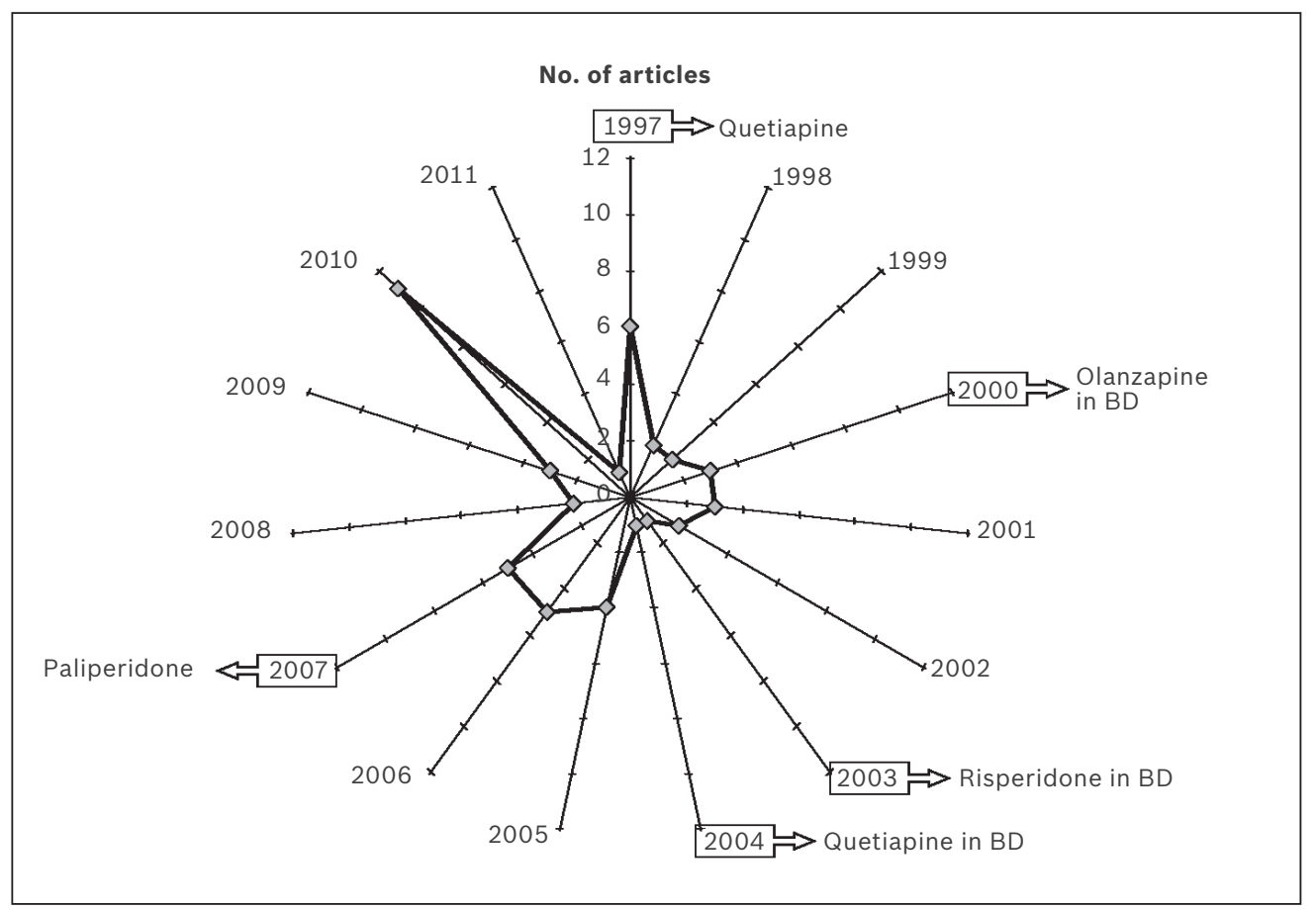

Fig. 1 Radar chart shows the annual number of articles published on second-generation antipsychotic drugs in Singapore from 1997 to 2011 with respect to the points of international authorisation of the various drugs. BD: bipolar disorder

in Singapore was in agreement with Price's Law of exponential growth, linear and exponential adjustments were made to the data obtained, using the following equations:

$$
\begin{array}{ll}
\text { Linear adjustment: } & y=0.125 x-2.4\left(r^{2}=0.0458\right) \\
\text { Exponential adjustment: } & y=2.4835 \mathrm{e}^{0.0102 \times}\left(r^{2}=0.0042\right)
\end{array}
$$

Similar adjustments were also made for total publications on antipsychotic drugs (typical and atypical) in Singapore. The following equations were used:

$$
\begin{array}{ll}
\text { Linear adjustment: } & y=0.2607 x-3.8476\left(r^{2}=0.1432\right) \\
\text { Exponential adjustment: } & y=3.8528 \mathrm{e}^{0.04 x}\left(r^{2}=0.1338\right)
\end{array}
$$

Bradford's Law was used as a bibliometric indicator of the dispersion of scientific information. With the aim of revealing the distribution of scientific literature in a particular discipline, Bradford proposed a model of concentric zones of productivity (termed as Bradford zones) with decreasing densities of information. ${ }^{(19)}$ Each of these zones would contain a similar number of articles, but with the number of journals in which these articles are published increasing as one passes from one zone to another. The model permits the identification of journals that are most widely used or have the greatest weightage in a given field of scientific production.

Impact factor (IF) was used as an indicator of the weight of the journal. The IF was developed as an indicator by the Institute for Scientific Information (Philadelphia, PA, USA), and it is published annually under the Journal Citation Reports (JCR) section of the Science Citation Index (SCI). The IF of a journal is calculated based on the number of times a journal has been cited in the source journals of the $\mathrm{SCl}$ during the previous two years, as well as the total number of articles published by the journal in question during the two-year period. The IF data for 2010, which was published in the 2011 JCR, (Journal Citation Reports, Thomson Reuters, 2011) was used in the present study.

The index of collaboration between authors (i.e. signatures/ document or authors/paper index) was also applied. This index shows the quotient between the number of authors and the total number of articles collected in the database. Another indicator included in our analysis was the national participation index (PI) of Singapore for overall scientific publication (i.e. the ratio of the number of articles generated by Singapore to the total number of articles on the topic). The PI of Singapore was compared with the global PI for biomedicine and health sciences, particularly the global PI for the areas of psychiatry and neurology. The PI was also correlated with the corresponding PIs of the world's ten most productive countries, in terms of scientific literature, during the years 1997-2011. Other comparisons included a correlation of the PI with health data such as total per capita expenditure on health and gross domestic expenditure on research and development (R\&D). Relevant health data were sourced from the publications of the Organisation of Economic and Co-operative Development Health Division ${ }^{(20)}$ and the World Health Organization's Department of Health Statistics and Informatics. ${ }^{(21)}$

\section{RESULTS}

From 1997 to 2011, we retrieved 51 articles from Singapore that dealt with various aspects of SGAs (21 on clozapine; 16 on risperidone; 8 on olanzapine; 4 on asenapine; 2 on quetiapine; 1 on paliperidone; 1 on sertindole), and 89 articles related to total antipsychotic drugs. No article on ziprasidone, aripiprazole, amisulpride, zotepine, iloperidone, lurasidone, perospirone or 


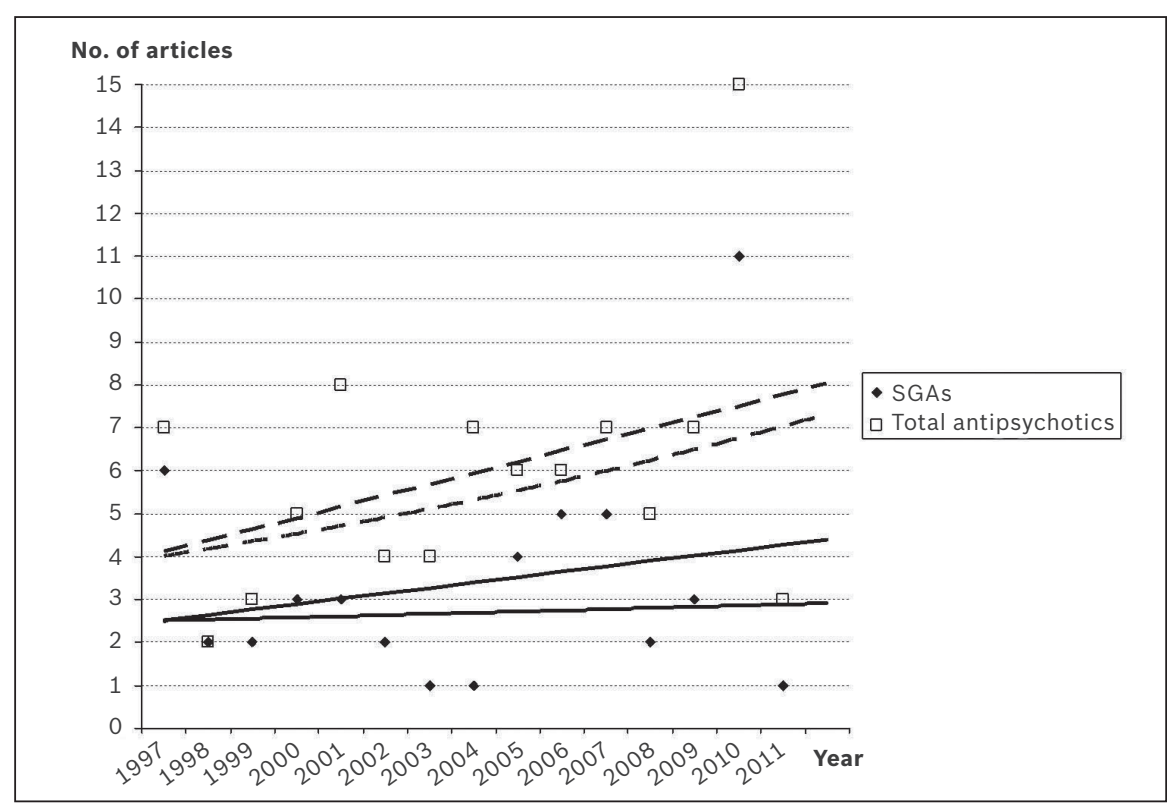

Fig. 2 Graph shows the growth of scientific literature on second-generation antipsychotic drugs (SGAs; solid line) and total antipsychotic drugs (dashed line) in Singapore. Linear and exponential adjustments were applied for the data on articles regarding SGAs and total antipsychotic drugs. In both cases, there was no compliance with Price's Law. ${ }^{(18)}$ Linear adjustment $(S G A s): y=0.125 x-2.4\left(r^{2}=0.0458\right)$; exponential adjustment $(S G A s)$ : $y=2.4835 e^{0.0102 x}\left(r^{2}=0.0042\right) ;$ linear adjustment (total antipsychotics): $y=0.2607 x-3.8476$ $\left(r^{2}=0.1432\right)$; exponential adjustment (total antipsychotics): $y=3.8528 e^{0.04 x}\left(r^{2}=0.1338\right)$

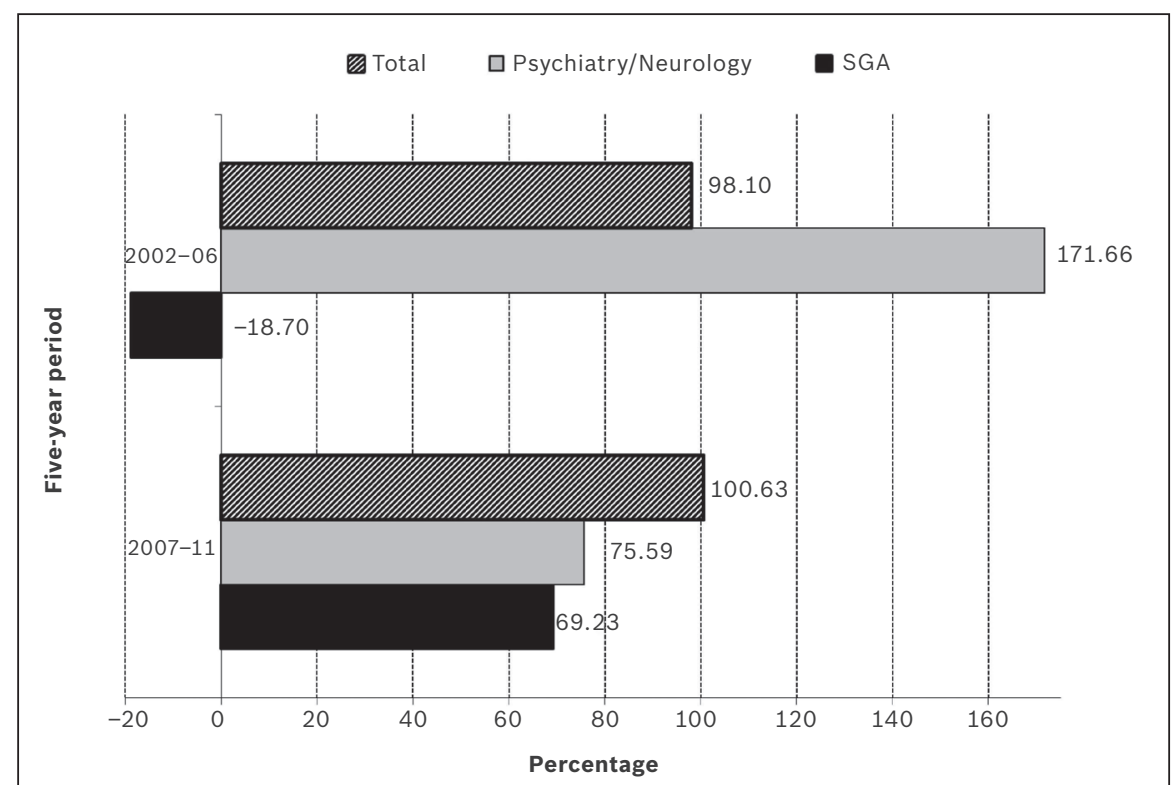

Fig. 3 Graph shows the five-year cumulative growth of scientific literature in Singapore with respect to total productivity in the fields of biomedicine and health sciences, psychiatry and neurology, and second-generation antipsychotic drugs (SGAs). Data in each five-year interval refers to evolution over the previous period. Note: The period of reference was 1997-2001 and the data is expressed in percentage values.

blonanserin was found. It should be noted that perospirone and blonanserin are not available in Singapore.

There has only been a slight increase in the number of publications on SGAs generated in Singapore over the last 15 years (Fig. 1). Mathematical adjustments to the exponential and linear curves confirmed that the increase in the literature for both SGAs and total antipsychotic drugs did not conform to the postulates of Price's Law, possibly due to the small sample of publications (Fig. 2). The relative five-year growth of publications on SGAs and total antipsychotics in Singapore during the period studied, with the 2007-2011 interval taken as reference, is shown in Fig. 3. The cumulative growth in the literature was lower than the overall global growth of scientific output in the field of biomedicine and health sciences, and slightly less in the specific field of psychiatry and neurology within Singapore.

Table II shows the results of the application of Bradford's model to the scientific journals in which articles on SGAs were 
Table II. Distribution of scientific literature on secondgeneration antipsychotic drugs in Singapore in Bradford zones.

\begin{tabular}{llll}
\hline $\begin{array}{l}\text { Bradford } \\
\text { zone }\end{array}$ & $\begin{array}{l}\text { No. of journals } \\
(\mathbf{n}=\mathbf{3 0})\end{array}$ & $\begin{array}{l}\text { No. of articles } \\
(\mathbf{n}=\mathbf{5 1 )}\end{array}$ & $\begin{array}{l}\text { Bradford } \\
\text { constants }\end{array}$ \\
\hline 1 & 2 & 10 & \\
2 & 3 & 9 & 1.5 \\
3 & 5 & 11 & 1.67 \\
4 & 9 & 10 & 1.8 \\
5 & 10 & 10 & 1.11 \\
6 & 1 & 1 & \\
\hline
\end{tabular}

The mean no. of articles per Bradford zone was 8.5. The mean no. of articles per Bradford zone when the last Bradford zone was excluded was 10.

Table III. The top six journals with the highest number of articles published on second-generation antipsychotic drugs in Singapore.

\begin{tabular}{llll}
\hline Journal name & $\begin{array}{l}\text { No. of } \\
\text { articles }\end{array}$ & $\begin{array}{l}\text { Participation } \\
\text { index }\end{array}$ & $\begin{array}{l}\text { Impact } \\
\text { factor* }\end{array}$ \\
\hline $\begin{array}{l}\text { Journal of Clinical } \\
\text { Psychopharmacology }\end{array}$ & 6 & 11.76 & 4.857 \\
$\begin{array}{l}\text { Singapore Medical Journal } \\
\text { Annals of the Academy }\end{array}$ & 4 & 7.84 & 0.730 \\
$\begin{array}{l}\text { of Medicine Singapore } \\
\begin{array}{l}\text { Australian and New Zealand } \\
\text { Journal of Psychiatry }\end{array}\end{array}$ & 3 & 5.88 & 1.203 \\
$\begin{array}{l}\text { International Journal of } \\
\text { Neuropsychopharmacology }\end{array}$ & 3 & 5.88 & 2.418 \\
$\begin{array}{l}\text { Human Psychopharmacology } \\
\text { Clinical and Experimental }\end{array}$ & 3 & 5.88 & 4.699 \\
\hline
\end{tabular}

${ }^{*}$ Data extracted from Journal Citation Reports, Thomson Reuters, 2011.

published. The mean number of articles per Bradford zone, when the last zone (which had a lower accuracy) was not taken into account, was 10 . The nucleus (i.e. the first zone) included the Journal of Clinical Psychopharmacology (6 articles) and Singapore Medical Journal (4 articles). The remaining journals that were analysed were included in zones 2-6. The analysed material was found to have been published in a total of 30 different journals. However, six journals accounted for $47.06 \%$ of all articles retrieved on our searches (Table III), and the journals most extensively used for the dissemination of research on SGAs had reasonably high IFs, with four journals having IF $>2$.

On manual classification, $37.26 \%$ of the articles retrieved were found to belong to the clinical efficacy group, $31.37 \%$ to the tolerance and/or safety group, $19.62 \%$ to the experimental pharmacology group and $11.65 \%$ to the not specified group (which mainly included reviews of different SGAs and articles on prescribing patterns). Clinical studies were mostly on schizophrenia $(n=12)$, with two on bipolar disorder. The collaboration index (i.e. quotient of studies with ' $\mathrm{n}$ ' signatories), which is indicative of the cooperation between authors during article production, was 4.54 authors/article and it was found to have increased during the study years by $13.66 \%$ (from 4.44 during the 1997-2001 five-year period to 5.04 during the 2007-2011 five-year period).
The general publication output on SGAs from Singapore $(\mathrm{PI}=0.32)$ was low when compared to the worldwide publication output during the period analysed. Table IV shows how Singapore compares with the top ten most productive countries in the fields of biomedicine and health sciences, and psychiatry and neurology. USA ( $\mathrm{PI}=31.63$ ), followed by the United Kingdom (UK), Germany, Canada, Italy and Spain were the six most productive countries in terms of publication output on SGAs. However, when the productivity of these countries on SGAs was assessed in relation to their overall productivity in the field of psychiatry and neurology, only Spain was found to have a higher percentage of research on SGAs (Fig. 4). Singapore occupied the third position in this ranking. The distribution obtained from the analysis of the correlation between PI and the per capita health expenditure of each of the aforementioned countries is shown in Fig. 5.

The most productive institutions in Singapore in relation to the material under study were the Institute of Mental Health of Woodbridge Hospital $(\mathrm{n}=24)$ and the National University of Singapore $(n=7)$, both accounting for $60.78 \%$ of the total production of literature on SGAs in Singapore. However, all inferences regarding the most productive institutions in Singapore were drawn solely based on the information available in the AD field in the EMBASE Biomedical Answer web database.

\section{DISCUSSION}

Bibliometric studies constitute interesting tools for assessing the social and scientific importance of a given discipline over a specific period of time. Despite their methodological limitations, these studies permit an overview of the growth, size and distribution of scientific literature related to a particular discipline, as well as the study of the evolution of not only the biomedical speciality, field of specialisation or issue in question, but also the scientific production of an institution, country, author or research group. Previous bibliometric studies have drawn attention to a series of limitations characteristic of this sociometric approach. ${ }^{(22)}$ For example, international scientific production in any particular field (e.g. SGAs, as is the case in the present study) is much more extensive than what is indexed in the usual databases (i.e. many journals or contributions made to scientific conferences and meetings are not indexed in such databases). Nevertheless, the recognised quality of the publications included in the databases selected for the present study and their extensive coverage imply that the articles retrieved from our searches would constitute more than a representative sample of the international research on the area in question.

Our study design allowed us to make a global assessment of the growth of the scientific literature on SGAs in Singapore. We found that the number of scientific publications on SGAs had only increased slightly in Singapore in recent years, with no evident exponential growth (correlation coefficient, $r=0.0648$ after exponential adjustment vs. $r=0.2140$ after linear adjustment), 
Table IV. The relative publication output on second-generation antipsychotic drugs (SGAs) of Singapore and the top ten most productive countries in biomedicine and health sciences, for the period 1997-2011.

\begin{tabular}{|c|c|c|c|c|c|}
\hline \multirow[t]{2}{*}{ Rank } & \multirow[t]{2}{*}{ Country } & \multicolumn{3}{|c|}{ Articles produced during 1997-2011 (\%) } & \multirow{2}{*}{$\begin{array}{l}\text { SGAs/Psychiatry } \\
\text { \& neurology }\end{array}$} \\
\hline & & $\begin{array}{l}\text { Biomedicine \& health } \\
\text { sciences }(n=11,678,458)\end{array}$ & $\begin{array}{l}\text { Psychiatry \& neurology } \\
\text { ( } n=1,265,556)\end{array}$ & $\begin{array}{l}\text { SGAs } \\
(n=16,019)\end{array}$ & \\
\hline 1 & USA & 25.85 & 39.71 & 31.63 & 1.03 \\
\hline 2 & UK & 7.44 & 10.86 & 6.92 & 0.81 \\
\hline 3 & Germany & 6.46 & 8.76 & 6.45 & 0.93 \\
\hline 4 & Japan & 6.43 & 7.19 & 3.82 & 0.67 \\
\hline 5 & China & 4.60 & 3.63 & 2.31 & 0.81 \\
\hline 6 & France & 4.50 & 5.25 & 3.17 & 0.76 \\
\hline 7 & Italy & 3.96 & 5.25 & 4.96 & 1.19 \\
\hline 8 & Canada & 3.79 & 5.59 & 5.14 & 1.17 \\
\hline 9 & Spain & 2.83 & 3.28 & 3.91 & 1.51 \\
\hline 10 & Australia & 2.59 & 3.50 & 2.66 & 0.96 \\
\hline- & Singapore & 0.37 & 0.33 & 0.32 & 1.23 \\
\hline
\end{tabular}

UK: United Kingdom; USA: United States of America

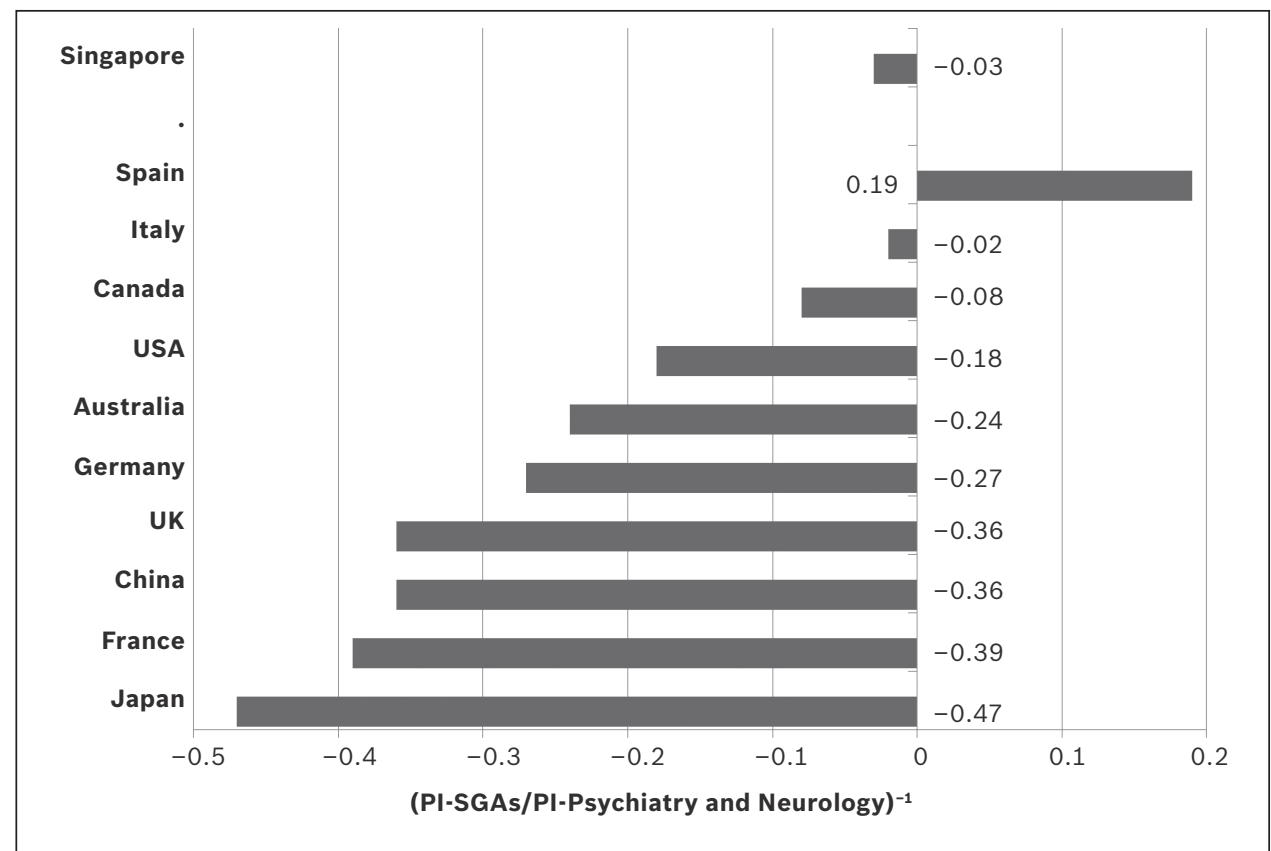

Fig. 4 Graph shows the relationship between the production of scientific literature on secondgeneration antipsychotic drugs (SGAs) and total production in the field of psychiatry and neurology in the world's ten most productive countries in biomedicine and health sciences, and Singapore. $\mathrm{PI}$ : participation index; UK: United Kingdom; USA: United States of America

mirroring patterns reported earlier for other emergent East Asian countries such as Taiwan and South Korea. ${ }^{(16,17)}$ Our inferences showed a close correlation with the prescription data reported in recent pharmacoepidemiological studies by the Research on Asian Psychotropic Prescription (REAP) project for countries in this region (e.g. China, Hong Kong, Japan, Korea, Singapore and Taiwan). ${ }^{(23,24)}$ According to Nakano et al, the prescribing patterns for SGAs showed a significant increase in the years 2001 (45.5\%), 2004 (64.7\%) and 2008 (76.6\%). ${ }^{(23)}$ However, in Singapore, Xiang et al reported that the corresponding increase was slower (2001, 6.7\%; 2004, 16.5\%; 2009, 50.0\%). ${ }^{(24)}$ The findings of these authors show a strong correlation with the results of the present study, as our analysis suggested that research on SGAs had grown in Singapore, although not exponentially.

The vast development seen in the scientific literature on SGAs has largely coincided with their approval for marketing by the US Food and Drug Administration (FDA) and other international regulatory agencies for the treatment of bipolar disorder. Since 2004, other SGAs such as risperidone, ziprasidone, quetiapine, aripiprazole and asenapine have been approved for the treatment of manic episodes, while olanzapine and aripiprazole have been approved for the prevention of relapse in patients with bipolar disorder. ${ }^{(25)}$ Quetiapine is indicated as monotherapy for the acute treatment of depressive episodes associated with bipolar disorder, and the olanzapine-fluoxetine combination 


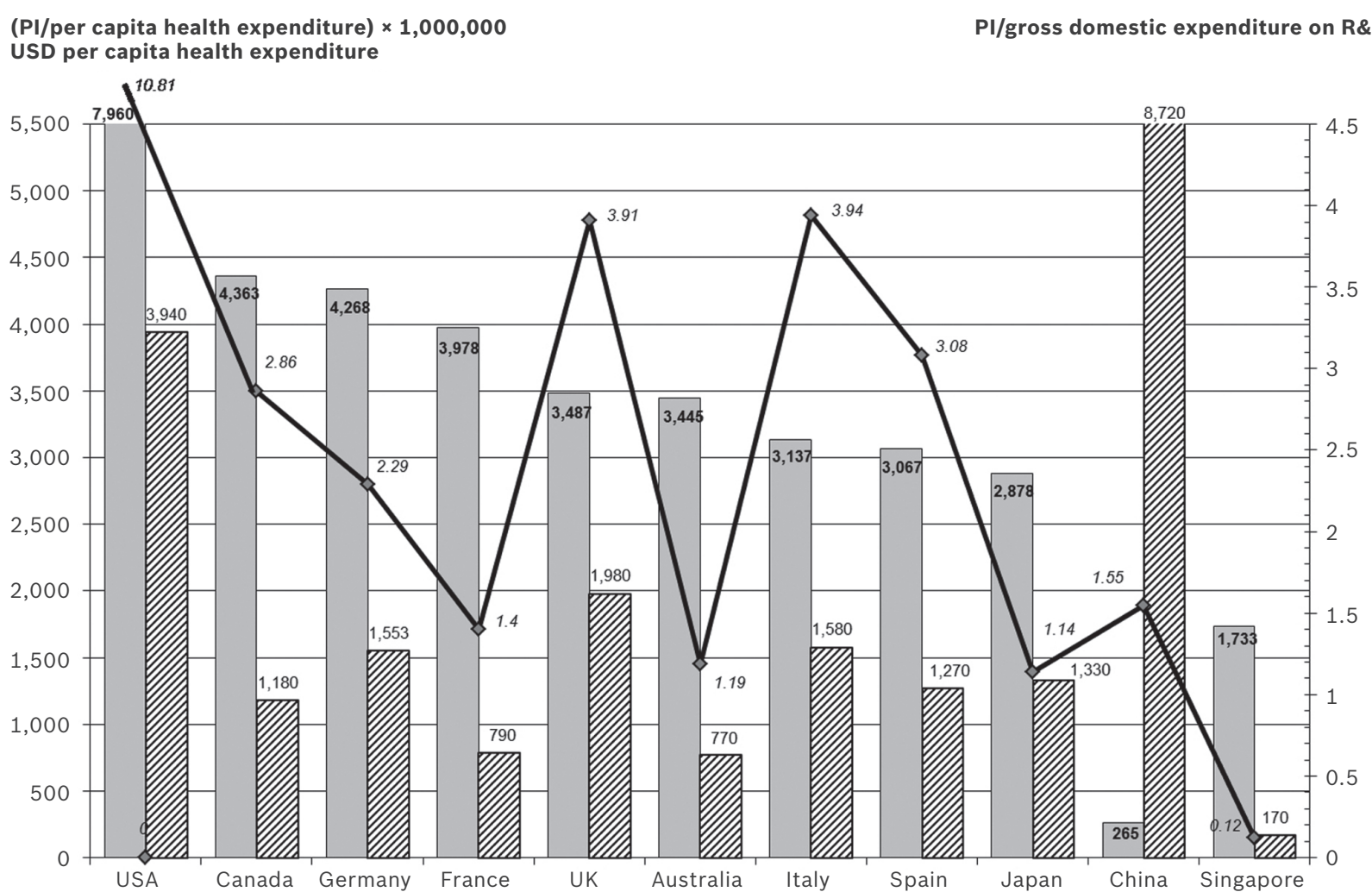

$\square$ Per capita health expenditure $\mathbf{m}$ (PI/total health expenditure per capita) $\times 1,000,000 \rightarrow$ PI/gross domestic expenditure on R\&D

Fig. 5 Graph shows the per capita health expenditure and the relationship between the production of scientific literature on secondgeneration antipsychotic drugs, and per capita health expenditure and gross domestic expenditure on R\&D in the world's ten most productive countries in biomedicine and health sciences, and Singapore.

Source: Data on total health expenditure per capita PPP USD from OECD $2009 ;^{(20)}$ data on Japan and Australia from OECD 2008 ; ${ }^{(20)}$ data on China and Singapore (in PPP International dollars) from WHO 2008. (21) Data on gross domestic expenditure on R\&D from OECD 2010,(20) except for USA and Japan (data from OECD 2009), ${ }^{(20)}$ China (data from OECD 2007), (20) and Singapore (data from Global Finance Magazine $2008 ;$ http://www.gfmag.com).

OECD: Organisation for Economic Co-operation and Development; PI: participation index; PPP: purchasing power parity; R\&D: research and development; UK: United Kingdom; USA: United States of America; USD: United States dollars; WHO: World Health Organization

has been recommended for treating treatment-resistant major depressive disorders. In addition, aripiprazole was approved in 2007 by FDA as an add-on to antidepressants for the treatment of treatment-resistant major depression. ${ }^{(25)}$ SGAs are also commonly used, and studied, in numerous off-label indications for conditions such as substance-induced psychosis, agitation symptoms, tics and substance-abuse disorders. ${ }^{(26,27)}$

Another aspect of interest in relation to scientific production that we analysed in the present study, is the quality of the publications. The fact that prestigious journals such as the Journal of Clinical Psychopharmacology (IF = 4.857) and the International Journal of Neuropsychopharmacology (IF = 4.699) published articles on SGAs from Singapore indicates the growing relevance of research in Singapore in the recent years. Notably, four among the six journals in which research was most widely cited had a significant impact in the field of psychiatry $(\mathrm{IF}>2)$.

As we have shown in earlier studies, ${ }^{(16,17)}$ scientific research on antipsychotic drugs is one of the fastest growing areas within the field of psychiatry. Other authors, with the use of bibliometric tools, have similarly reported more extensive research on schizophrenia than other fields of psychiatry. ${ }^{(28)}$
According to Clement et al, the more expansive investigation on schizophrenia may have positive correlations with the clinical perception that this illness is more serious than other psychiatric pathologies. ${ }^{(28)}$ Theander and Wetterberg reported that the number of citations on schizophrenia in the MEDLINE database (which accounted for $0.42 \%$ of the total literature published during the period studied) reflected the general increase in the number of medical publications. ${ }^{(29)}$

With regard to the $\mathrm{PI}$ of the different countries in the production of scientific literature on SGAs, USA and UK, two major English-speaking countries, head the ranking; these two countries generate over a third of the total scientific publication in the field $(38.55 \%)$. The fact that these two countries are home to many of the major pharmaceutical companies responsible for the development of SGAs (e.g. Eli Lilly - olanzapine; Janssen Pharmaceutica - risperidone and paliperidone; AstraZeneca - quetiapine; Pfizer - ziprasidone; Bristol-Myers Squibb/Otsuka Pharmaceutical - aripiprazole) may explain these countries' high PIs. In the other countries that appear near the top in the ranking for production of scientific literature on SGAs with respect to general productivity in the field of psychiatry and neurology (e.g. Spain, Italy and Canada), 
their high ranking is a reflection of the importance given by these countries to research on SGAs. A similar finding can be observed in Singapore, where although scientific production on SGAs is small, it is important in the field of psychiatry and neurology. Chong et $\mathrm{al}^{(30)}$ noted that the impact of research on mental health in Singapore is not evident, and that there was a relatively lower interest in SGAs in other East Asian countries such as Japan. The factors influencing the paucity of psychiatric research in Singapore are many, including Singapore's low psychiatrist-to-population ratio (2.6 per 100,000 population), the shortage of other mental health professionals (e.g. psychiatric nurses, clinical psychologists and psychiatric case managers), the general perception that psychiatrists get lower monetary remunerations than other medical specialists, the inclination of psychiatric centres to cater more to clinical services, the larger stigma associated with mental illness in Singapore, as well as the continued and relatively high consumption of traditional medicines in the country. ${ }^{(9)}$

The correlation of the production of scientific literature on SGAs with the per capita health expenditure of each country offered a different perspective to our findings. In general, there was confirmation of the perception that the higher the spending on health, the greater a country's research production. However, it was striking to note the low ratios of countries such as Australia, France and Singapore. In spite of Singapore having the world's third highest gross domestic product per capita (purchasing power parity of USD 59,936), the country had relatively prudent health expenditure when compared to other developed countries. The correlation analysis of the production of scientific literature on SGAs and gross domestic expenditure on R\&D revealed that France, Australia, Japan and Singapore occupied the bottom four positions.

In terms of pharmacoepidemiological observations in published studies, there has been an overall increase in the prescription of SGAs over time for the management of psychotic disorders such as schizophrenia in Singapore, as compared to the prescription of first-generation antipsychotics. ${ }^{(30,31)}$ This is consistent with similar trends in Asia. ${ }^{(32)}$ Sim et al have even reported the use of SGAs to be associated with the use of lower doses of antipsychotic drugs. ${ }^{(33)}$ With regard to specific SGAs, data on clozapine use in Singapore showed some increase in prescription, and this contributed to the analyses within the REAP study, which associated the use of clozapine with more severe illness (i.e. more frequent admissions, greater severity of delusions, disorganisation, negative symptoms) but with less EPS. ${ }^{(34)}$

When reviewing and assimilating the results of the present study, it would be prudent to exercise caution against overinterpreting its findings in view of its inherent limitations. First, articles where the team of authors included authors from Singapore were selected for inclusion irrespective of whether they were based overseas or in Singapore. Such a criterion, however, may have led to the exclusion of articles in which the authors did not specify an affiliation with a specific clinical or academic institute in Singapore. To minimise this, we sought the help of various individuals familiar with relevant research literature from Asia and Singapore, as well as searched for relevant articles using various search engines, including the MEDLINE, EMBASE and Biomedical Answer web databases. Second, the use of IF as an indicator of the merit or quality of scientific contributions is still a matter of much debate. A low citation count might not necessarily mean that the article was less impactful - it could mean that the given topic of study is 'not yet mature' and that other studies are still ongoing. Third, only studies published during 1997-2011 were included in our review, thus excluding other efforts conducted or published prior to this period. Nonetheless, in spite of the present study's many limitations, bibliometric studies are useful for assessing the social and scientific relevance of a given discipline or field. Bibliometric studies constitute an effective complement to the opinions and judgements of experts in every field, and can provide useful and objective data for evaluating the results of scientific activity, offering realistic indications of trends, as well as predicting how such trends might evolve over time.

In conclusion, the present study provides a glimpse into the evolution of research on SGAs in Singapore vis-à-vis the parameters of quality and dissemination that are most commonly used at an international level. SGAs formed the top drug class in terms of market share (USD 14.6 billion per year) in the year 2008 in USA. ${ }^{(25)}$ Given the ever-growing importance of this class of drugs, the fact that an ideal antipsychotic drug has yet to be found, ${ }^{(7)}$ and the fact that the exact aetiopathogenesis of schizophrenia remains to be revealed, we are of the opinion that research on SGAs will continue to grow in the coming years.

\section{REFERENCES}

1. Goldner EM, Hsu L, Waraich P, Somers JM. Prevalence and incidence studies of schizophrenia disorder: a systematic review of literature. Can J Psychiatry 2002; 47:833-43.

2. World Health Organization. Mental Health: New Understanding, New Hope. Geneva: WHO, 2001.

3. López-Muñoz F, Alamo C, Cuenca E, et al. History of the discovery and clinical introduction of chlorpromazine. Ann Clin Psychiatry 2005; 17:113-35.

4. Shen WW. A history of antipsychotic drug development. Compr Psychiatry 1999; 40:407-14.

5. Kane J, Honigfeld G, Singer J, Meltzer H. Clozapine for the treatmentresistant schizophrenic. A double-blind comparison with chlorpromazine. Arch Gen Psychiatry 1988; 45:780-96.

6. Hippius H. A historical perspective of clozapine. J Clin Psychiatry 1999; 60 (Suppl 12):22-3.

7. López-Muñoz F, Álamo C. Neurobiological background for the development of new drugs in schizophrenia. Clin Neuropharmacol 2011; 34:111-26.

8. López-Muñoz F, Vieta E, Rubio G, García-García P, Álamo C. Bipolar disorder as an emerging pathology in the scientific literature: a bibliometric approach. J Affect Disord 2006; 92:161-70.

9. Chong SA. Mental health in Singapore: a quiet revolution? Ann Acad Med Singapore 2007; 36:795-6.

10. Verma S, Chan LL, Chee KS, et al. Ministry of Health clinical practice guidelines: schizophrenia. Singapore Med J 2011; 52:521-5.

11. Mok YM, Chan HN, Chee KS, et al. Ministry of Health clinical practice guidelines: bipolar disorder. Singapore Med J 2011; 52:914-9. 
12. White HD, McCain KW. Bibliometrics. Ann Rev Inf Sci Technol 1989; 24:119-86.

13. López-Muñoz F, Álamo C, Rubio G, et al. Bibliometric analysis of biomedical publications on SSRIs during the period 1980-2000. Depress Anxiety 2003; 18:95-103.

14. López-Muñoz F, Álamo C, Quintero-Gutiérrez FJ, García-García P. A bibliometric study of international scientific productivity in attention-deficit hyperactivity disorder covering the period 1980-2005. Eur Child Adolesc Psychiatry 2008; 17:381-91.

15. López-Muñoz F, García-García P, Sáiz-Ruiz J, et al. A bibliometric study of the use of the classification and diagnostic systems in psychiatry over the last 25 years. Psychopathology 2008; 41:214-25.

16. López-Muñoz F, Shen WW, Moreno R, et al. International scientific productivity on second-generation antipsychotic drugs in Taiwan: a bibliometric study. Taiwanese J Psychiatry 2012; 26:114-29.

17. López-Muñoz F, Shen WW, Pae CU, et al. Trends in scientific literature on atypical antipsychotic drugs in South Korea: A bibliometric study. Psychiatr Invest 2013; 10:8-16.

18. Price DJS. Little Science, Big Science. New York: Columbia University Press; 1963.

19. Bradford SC. Documentation. London: Crosby Lockwood; 1948.

20. Organization for Economic and Co-operational Development Health Division. OECD Health Data 2011: Frequently Requested Data (June 30, 2011). Paris: OECD; 2011.

21. World Health Organization. WHO Department of Health Statistics and Informatics, 2011: World Health Statistics 2011 (May 13, 2011). Geneva: WHO, 2011.

22. Johnson $\mathrm{MH}$, Cohen J, Grudzinskas G. The uses and abuses of bibliometrics. Rep BioMed Online 2012; 24:485-6.

23. Nakano W, Yoshimura R, Yang S. The characteristics of pharmacotherapy for inpatients with schizophrenia: a multicentre comparative study in Asia.
Eur Neuropsychopharmacol 2010; 20:S467-8.

24. Xiang YT, Wang CY, Si TM, et al. Antipsychotic polypharmacy in inpatients with schizophrenia in Asia (2001-2009). Pharmacopsychiatry 2012; 45:7-12

25. Shen WW. Clinical Psychopharmacology for the 21 Century, Third Edition (in Chinese). Taipei: Ho-Chi Publishing Company; 2011.

26. Fountoulakis KN, Nimatoudis I, lacovides A, Kaprinis G. Off-label indications for atypical antipsychotics: a systematic review. Ann Gen Hosp Psychiatry 2004; 3:4.

27. Mortimer AM, Shepherd CJ, Rymer M, Burrows A. Primary care use of antipsychotic drugs: an audit and intervention study. Ann Gen Psychiatry 2005; 4:18-26.

28. Clement S, Singh S, Burns T. Status of bipolar disorder research. Bibliometric study. Br J Psychiatry 2003; 182:148-52.

29. Theander SS, Wetterberg L. Schizophrenia in Medline 1950-2006: a bibliometric investigation. Schizophr Res 2010; 118:279-84.

30. Chong MY, Tan $\mathrm{CH}$, Fujii S, et al. Antipsychotic drug prescription for schizophrenia in East Asia: rationale for change. Psychiatry Clin Neurosci 2004; 58:61-7.

31. Sim K, Su HC, Fujii S, et al. Low doses of antipsychotic drugs for hospitalized schizophrenia patients in East Asia: 2004 vs. 2001. Int J Neuropsychopharmacol 2009; 12:117-23.

32. Tan $\mathrm{CH}$, Shinfuku N, Sim K. Psychotropic prescription practices in East Asia: looking back and peering ahead. Curr Opin Psychiatry 2008; 21:645-50.

33. Sim K, Su HC, Fujii S, et al. High-dose antipsychotic use in schizophrenia: a comparison between the 2001 and 2004 Research on East Asia Psychotropic Prescription (REAP) studies. Br J Clin Pharmacol 2009; 67:110-7.

34. Xiang YT, Wang CY, Si TM, et al. Clozapine use in schizophrenia: findings of the Research on Asia Psychotropic Prescription (REAP) studies from 2001 to 2009. Aust N Z J Psychiatry 2011; 45:968-75.

\section{APPENDIX}

\section{References of articles used in this bibliometric study, according to year of publication}

1. Xiang YT, Wang CY, Si TM, et al. Clozapine use in schizophrenia: Findings of the Research on Asia Psychotropic Prescription (REAP) studies from 2001 to 2009. Aust N Z J Psychiatry 2011; 35:968-75.

2. Ahmad MT, Prakash KM. Reversible hyperkinetic movement disorder associated with quetiapine withdrawal. Mov Disord 2010; 25:1308-9.

3. Choi YK, Gardner M, Moran-Gates T, Henry B, Shahid M, Tarazi FI. Ex vivo analysis of asenapine-, olanzapine-, and risperidone-induced dopamine $\mathrm{d} 1$ and $\mathrm{d} 2$ receptor occupancy in rat brain. Schizophr Res 2010; 117:510-1.

4. Choi YK, Henry B, Shahid M, Tarazi F. Ex-vivo serotonin 5-HT1A and 5-HT2A receptor occupancy by asenapine: Comparison to olanzapine and risperidone. Eur Neuropsychopharmacol 2010; 20:S260-1.

5. Choi YK, Wong EH, Henry B, Shahid M, Tarazi FI. Repeated effects of asenapine on adrenergic and cholinergic muscarinic receptors. Int J Neuropsychopharmacol 2010; 13:405-10.

6. Kwan Y, Sim K. Resolution of tardive dystonia in a patient with bipolar disorder treated with clozapine: a case report. Prog Neuropsychopharmacol Biol Psychiatry 2010; 34:238-9.

7. Liew A, Verma S, Poon LY, et al. Comparing effectiveness of risperidone with first-generation antipsychotic medications in patients with schizophrenia-spectrum disorders. J Psychopharmacol 2010; 24:973-80.

8. Mahendran R, Hendricks M, Chan YH. Weight gain in Asian patients on second-generation antipsychotics. Ann Acad Med Singapore 2010; 39:118-21.

9. Nelleman L, Kwon JS, Ong A, Mittoux A, Cai ZJ, Su TP. The efficacy and safety of 12-week treatment with sertindole or olanzapine in asian patients with schizophrenia; a randomised, double-blind, parallel-group, flexible-dose study. J Neurochem 2010; 115:57.

10. Thavichachart N, Conde B, Sobrevega E, et al. Efficacy and tolerability study of flexibly dosed paliperidone ER in ASEAN schizophrenia patient who previously unsuccessfully treated with other oral antipsychotics. Int J Neuropsychopharmacol 2010; 13:243.

11. Verma S, Subramaniam M, Abdin E, et al. Safety and efficacy of long-acting injectable risperidone in patients with schizophrenia spectrum disorders:
A 6-month open-label trial in Asian patients. Hum Psychopharmacol 2010; 25:230-5

12. Wee JCP, Wong E, Annathurai A. A case of risperidone-associated neuroleptic malignant syndrome in a patient receiving long-term haloperidol treatment. Hong Kong J Emerg Med 2010; 17:285-8.

13. Gray L, Van Den Buuse M, Scarr E, Dean B, Hannan AJ. Clozapine reverses schizophrenia-related behaviours in the metabotropic glutamate receptor 5 knockout mouse: Association with N-methyl-daspartic acid receptor up-regulation. Int J Neuropsychopharmacol 2009; 12:45-60.

14. Shahid $M$, Henry B. Characterization of $[3 \mathrm{H}]$ asenapine binding in sections of rat brain. J Cancer Educ 2009; 24:S565-6.

15. Tan HH, Hoppe J, Heard K. A systematic review of cardiovascular effects after atypical antipsychotic medication overdose. Am J Emerg Med 2009; 27:607-16.

16. Ngo A, Ciranni M, Olson KR. Acute quetiapine overdose in adults: A 5-year retrospective case series. Ann Emerg Med 2008; 52:541-7.

17. Peh AL. Safety monitoring of patients on atypical antipsychotics. Qual Saf Health Care 2008; 17:469-72.

18. Lim EP, Verma V, Nagarajah R, Dawe GS. Propranolol blocks chronic risperidone treatment-induced enhancement of spatial working memory performance of rats in a delayed matching-to-place water maze task. Psychopharmacology (Berl) 2007; 191:297-310.

19. Mahendran R, Liew E, Subramaniam M. De novo emergence of obsessivecompulsive symptoms with atypical antipsychotics in Asian patients with schizophrenia or schizoaffective disorder: a retrospective, cross-sectional study. J Clin Psychiatry 2007; 68:542-5.

20.Subramaniam M, Ng C, Chong SA, et al. Metabolic differences between Asian and Caucasian patients on clozapine treatment. Hum Psychopharmacol 2007; 22:217-22.

21. Thinn SS, Liew E, May AL, Chua HC, Sim K. Reversible delayed onset olanzapine-associated leukopenia and neutropenia in a clozapine-naive patient on concomitant depot antipsychotic. J Clin Psychopharmacol $2007 ; 27: 394-5$ 
22. Verma V. Lim EP, Han SP, Nagarajah R, Dawe GS. Chronic high-dose haloperidol has qualitatively similar effects to risperidone and clozapine on immediate-early gene and tyrosine hydroxylase expression in the rat locus coeruleus but not medial prefrontal cortex. Neurosci Res 2007; 57:17-28.

23. Remington G, Saha A, Chong SA, Shammi C. Augmenting strategies in clozapine-resistant schizophrenia. CNS Drugs 2006; 20:171.

24. Rourke C, Starr KR, Reavill C, et al. Effects of the atypical antipsychotics olanzapine and risperidone on plasma prolactin levels in male rats: A comparison with clinical data. Psychopharmacology (Berl) 2006; 184:107-14.

25. Sim K, Yong TW, Liew E, Choon HC. Clozapine-associated pseudomembranous colitis: a case report and review of the literature. Clin Psychopharmacol 2006; 26:89.

26. Sitoh YY. Atypical antipsychotic medications and risk of falls (comment). J Am Geriatr Soc 2006; 54:174-5. Comment on: J Am Geriatr Soc 2005; 53:1290-5

27. Verma V, Rasmussen K, Dawe GS. Effects of short-term and chronic olanzapine treatment on immediate early gene protein and tyrosine hydroxylase immunoreactivity in the rat locus coeruleus and medial prefrontal cortex. Neuroscience 2006; 143:573-85.

28. Freudenmann RW, Schonfeldt-Lecuona C, Yew TJ. Delusional parasitosis: Treatment with atypical antipsychotics (comment). Ann Acad Med Singapore 2005; 34:141-2. Comment on: Ann Acad Med Singapore 2004; 33:89-94.

29. $\mathrm{Ng} \mathrm{CH}$, Chong SA, Lambert T, et al. An inter-ethnic comparison study of clozapine dosage, clinical response and plasma levels. Int Clin Psychopharmacol 2005; 20:163-8.

30. Remington G, Saha A, Chong SA, Shammi C. Augmentation strategies in clozapine-resistant schizophrenia. CNS Drugs 2005; 19:843-72.

31. Verma SK, Tan $\mathrm{CH}$, Chan YH, Chong SA. Plasma risperidone levels and clinical response in patients with first-episode psychosis. J Clin Psychopharmacol 2005; 25:609-11.

32. Luo N, Koh Y, Tan CH, Kua EH, Li SC. Drug utilization review of risperidone for outpatients in a tertiary referral hospital in Singapore. Hum Psychopharmacol 2004; 19:259-64.

33. Sathirakul K, Chan C, Teng L, et al. Olanzapine pharmacokinetics are similar in Chinese and Caucasian subjects. Br J Clin Pharmacol 2003; 56:184-7.

34. Mahendran R. Emergence of compulsive symptoms with olanzapine treatment. Aust N Z J Psychiatry 2002; 36:565.
35. Mahendran R. Leucopenia and thrombocytopenia induced by clozapine. Hong Kong J Psychiatry 2002; 12:19-24.

36. Chua L, Chong SA, Pang E, Ng VP, Chan YH. The effect of risperidone on cognitive functioning in a sample of Asian patients with schizophrenia in Singapore. Singapore Med J 2001; 42:243-6.

37. Mahendran R. Clozapine in the treatment of hypomania with neurosyphilis. J Clin Psychiatry 2001; 62:477-8.

38. Yap HL, Mahendran R, Lim D, et al. Risperidone in the treatment of first episode psychosis. Singapore Med J 2001; 42:170-3.

39. Chong SA, Remington G. Clozapine augmentation: safety and efficacy. Schizophr Bull 2000; 26:421-40.

40. Chong SA, Remington GJ, Bezchlibnyk-Butler KZ. Effect of clozapine on polypharmacy. Psychiatr Serv 2000; 51:250-2.

41. Chong SA, Remington GJ, Lee N, Mahendran R. Contrasting clozapine prescribing patterns in the east and west? Ann Acad Med Singapore 2000; 29:75-8.

42. Chong SA, Yap HL, Low BL, et al. Clinical evaluation of risperidone in Asian patients with schizophrenia in Singapore. Singapore Med J 1999; 40:41-3.

43. Lee HS, Tan CH, Khoo YM, et al. Serum concentrations and clinical effects of risperidone in schizophrenic patients in Singapore -- a preliminary report. Br J Clin Pharmacol 1999; 47:460-1.

44. Chong SA, Remington G. Ethnicity and clozapine metabolism. Br J Psychiatry 1998; 172:97.

45. Mahendran R. Obsessional symptoms associated with risperidone treatment. Aust N Z J Psychiatry 1998; 32:299-301.

46. Chong SA, Chua L. Clozapine, Chinese and blood. Br J Psychiatry 1997; 170:89-90.

47. Chong SA, Tan $\mathrm{CH}$, Lee HS. Atrial ectopics with clozapine-risperidone combination. J Clin Psychopharmacol 1997; 17:130-1.

48. Chong SA, Tan $\mathrm{CH}$, Lee HS. Worsening of psychosis with clozapine and selective serotonin reuptake inhibitor combination: two case reports. J Clin Psychopharmacol 1997; 17:68-9.

49. Chong SA, Tan $\mathrm{CH}$, Khoo YM, et al. Clinical evaluation and plasma clozapine concentrations in Chinese patients with schizophrenia. Ther Drug Monit 1997; 19:219-23.

50. Lee HS, Tan CH, Au LS, Khoo YM. Serum and urine risperidone concentrations in an acute overdose. J Clin Psychopharmacol 1997; 17:325-6.

51. Wong KE, Chong SA, Ngui F, et al. Initial experience with clozapine in Woodbridge Hospital. Singapore Med J 1997; 38:336-8. 